CDD: 303.4833

\title{
A INCLUSÃO ÉTNICO-RACIAL NA ERA DA INFORMAÇÃO
}

\section{THE ETHNIC-RACIAL INCLUSION IN THE INFORMATION AGE}

\section{Mirian de Albuquerque Aquino ${ }^{1}$}

Resumo: O texto aborda o contexto das tecnologias intelectuais como uma necessidade premente para afrodescendentes enfrentarem um mundo de incertezas, esperanças e responsabilidades. Discute os efeitos negativos e positivos das tecnologias e as exclusões persistentes no acesso e uso da informação digital pela população negra. A representação de afrodescendentes na ciência é pouco significativa, sendo vistos mais como objetos do que como sujeitos. Sua formação técnico-científica ainda é precária para filtrar a informação e gerar conhecimento na produção de tecnologias cada vez mais sofisticadas. $\mathrm{O}$ acesso e o uso da informação não democratizam a educação, nem favorecem o crescimento das oportunidades de participação concreta de afrodescendentes na cultura digital.

Palavras-chave: Educação. Ciência. Tecnologias Intelectuais. Inclusão étnico-racial. Afrodescendentes. Era da Informação.

Abstract: This article deals with the relations among black women/men, Science and education, placing them in the context of intellectual technologies, as a pressing need to Afrodescendants to face up a world of uncertainties, hopes and responsibilities. It discusses the negative and positive effects of technologies and the persistent exclusions in the access and use of the digital information by the black population. The representation of the afrodescendants in Science is not much significant, since they are still seen as objects instead of subjects. The technical scientific education of black population is still precarious in order to filter the information and to generate knowledge in the production of increasingly sophisticated technologies. The access and use of information neither democratize the education nor encourage the growth of opportunities for the concrete participation of Afrodescendants in the digital culture.

Keywords: Education. Science. Intellectual Technology. Ethnic-Racial Inclusion. Afro descendants. Information Age.

\footnotetext{
${ }^{1}$ Doutora em Educação. Professora do Departamento de Ciência da Informação. Professora do Programa de Pós-graduação em Ciência da Informação. UFPB. E-mail: miriabu@ gmail.com Enviado em: 28/06/2012 - Aceito em: 03/03/2013.
} 


\section{INTRODUÇÃO}

As tecnologias sempre existiram. Sem dúvida, as revoluções sempre estiveram presentes na história da humanidade, mas nenhuma delas é comparada ao que costumam denominar hoje de "tecnologias da informação e comunicação" ou “tecnologias digitais”, “tecnologias intelectuais. É irreconciliável desconsiderar o momento histórico de produção das tecnologias, cujas dinâmicas e efeitos alteraram o cotidiano das pessoas, as relações entre os sujeitos, encurtaram as distâncias, mudaram as noções de tempo e espaço, e impuseram novos papéis para a informação e o conhecimento. As relações produzidas pelas tecnologias implicam perceber incertezas, exclusões, responsabilidades e esperanças.

A expressão tecnologias intelectuais utilizada doravante justifica seu uso pela capacidade de expandirem a mente humana e estimularem a criatividade. São tecnologias que se diferenciam das anteriores pela velocidade, penetrabilidade e flexibilidade, avançando sem interrupção numa lógica técnico-científica acelerada que transformou a cultura material pela combinação de um conjunto de elementos organizados em torno da tecnologia da informação (CASTELLS, 1999).

As rápidas transformações permitiram o aparecimento do microprocessador (1970) e da multimídia contemporânea (1980) não mais concentrando seus esforços nos conhecimentos e informação, mas em sua aplicação para produzir novos conhecimentos, numa dinâmica que circula entre a inovação e o uso. A década de 1990 irá marcar o aperfeiçoamento e a sofisticação dos aparatos tecnológicos, tornando o acesso e uso do computador e da internet cada vez mais simples para um maior número de pessoas, dotadas de poder aquisitivo mais elevado. Em alguns casos, dispensando a necessidade adquirir-se competência técnica avançada para a realização de tarefas pessoais e profissionais, de forma que operar um computador e acessar a internet já não é mais uma impossibilidade para o ser humano.

Os novos objetos de comunicação têm permitido o acesso e o uso de diferentes dispositivos computacionais/informacionais (comunicação por meio de e-mails, chat, blogs e a realização de fóruns, conferências e comunidades virtuais), impulsionados pelo desenvolvimento de materiais avançados, fontes de energia, técnicas de produção, nanotecnologia, tecnologias de transporte, entre outros. O "novo modo de desenvolvimento" (CASTELLS, 1999) exige que as sociedades emergentes 
conectem-se cada vez mais digitalmente, como um dos critérios fundamentais para a sua sobrevivência no sistema capitalista informacional. As relações entre criadores e produtores das tecnologias intelectuais pressionam as nações em busca de alternativas econômicas, políticas e sociais para se integrarem nessa sociedade em que o acesso e o uso da informação são formas de participarem, ativamente, da economia globalizada baseada na informação e no conhecimento.

Em decorrência desse novo desenvolvimento tecnológico, incessante, flexível e descentralizado, as sociedades humanas puderam se deslocar da oralidade primária, passando pela escrita rupestre, para viverem o estágio da imprensa e experimentarem o que Lèvy (1993) concebeu como três tempos do espírito: o oral, a escrita e o digital, produzidos numa linguagem na qual a informação pode ser produzida, armazenada, recuperada, processada, organizada, disseminada e democratizada para alcançar povos e nações. Neste cenário, os sujeitos criam e recriam as tecnologias. Aprendem usando as tecnologias, produzem novas tecnologias; reconfiguram as tecnologias já existentes e fazem novas aplicações. Os sujeitos produzem, utilizam e interpretam seus produtos, dando-lhes diferentes formas e significações culturais (OLIVEIRA, 2010). Este é um dos aspectos positivos das tecnologias.

Entretanto, entre os aspectos negativos, pelo menos três podem ser ressaltados: 1) a competência de "aprender a aprender" (DELORS, 1999) produzindo novas tecnologias afetou, brutalmente, os grupos excluídos, sobretudo, os afrodescendentes. Suas reais chances de conseguirem uma formação técnico-científica compatível com as exigências da educação contemporânea estam cada vez mais reduzidas diante dos índices de desigualdades raciais já conhecidos nos domínios político, econômico, social e educacional; 2) as tecnologias também podem ser acessadas e utilizadas para o exercício de atividades ilícitas e antigas discriminações e racismos que ferem o sentido da moralidade e da ética; 3 ) as tecnologias intelectuais também possibilitam a representação de diversos grupos sociais, inclusive dos afrodescendentes por meio de imagens distorcidas e caricatas.

As condições de produção, oferecidas aos sujeitos para interagirem com as tecnologias, não são iguais para todos. Poucos são os que delas se beneficiam. Ao aceitarmos que o acesso e o uso das tecnologias intelectuais abrangem igualmente todos os grupos sociais, esquivamo-nos de preconceitos, discriminações e racismos na 
partilha dos bens tecnológicos. Estas são exatamente as práticas e representações, designadas como incertezas de inclusões. Os sujeitos fazem a história das tecnologias e nelas incluem as possibilidades de exclusões e, assim, frustram as esperanças de inclusão digital nessa era da informação.

As tecnologias intelectuais não aumentam as oportunidades de inclusão digital nem cria as condições favoráveis para uma maior empregabilidade, redução da exclusão e diminuição da violência contra afrodescendentes.

Este artigo organiza-se em três aspectos: Primeiramente, abordarei as relações entre afrodescendentes e tecnologias, a seguir tratarei da relação entre afrodescendentes e ciência e, finalmente, a relação entre afrodescendentes e inclusão digital/etnicorracial. O segundo ponto centra-se no problema da relação entre afrodescendentes e ciência, que considerarei como o segundo desdobramento da temática central e, para caminhar nessa direção, colocarei uma questão: Como afrodescendentes podem manter de forma flexível e adaptável a dinâmica de continuar aprendendo a fazer ciência? O terceiro aspecto discute a relação entre afrodescendentes e inclusão digital, fazendo uma breve retomada dos primórdios das tecnologias na educação, conectando-as aos novos papéis assumidos pela informação e o conhecimento e sua relação com a educação nesta atual sociedade "intensiva em conhecimento".

\section{REPRESENTAÇÃO DE NEGROS NA CIÊNCIA}

Inúmeros são os estudiosos que abordam os avanços de áreas científicas tais como a biociência, a inteligência artificial, a informática, a antropologia, a ecologia e suas implicações na produção de conhecimento nas universidades e na emergência dos novos processos de aprendizagem em todas as áreas do saber (ASSMANN, 2001) (LÉVY, 1993), (CASTELLS, 1999). Contudo, a representação de negros é pouco significativa na ciência. Eles muitas vezes são vistos e analisados como objetos ou como sujeitos.

Para Cunha Júnior (2010) a presença de uma massa crítica de intelectuais negros nas universidades, nos institutos de pesquisa e nos órgãos financiadores de projetos é mínima. Ele chama a atenção para a necessidade premente de 
transformação da consciência coletiva da comunidade científica quanto aos temas de interesse dos afrodescendentes e sua inserção positiva na ciência que produzem.

O que os pesquisadores fazem nos laboratórios e núcleos de pesquisa estão expressos no Curriculum Lattes, mas ao abordarem a temática étnico-racial, muitas vezes, produzem uma "ciência sem consciência", deixando de considerar "múltiplas dimensões cosmológicas, místicas, sociológicas, pedagógicas" (XAVIER, 2006, p. 131) e tecnológicas da ciência afrocêntrica.

Nesta malha de imposição de acesso e uso das tecnologias intelectuais para aprender a produzir novos conhecimentos, articulam-se programas de macropesquisa e grandes mercados, desenvolvidos pelos governos com inovação descentralizada para estimular a cultura de criatividade tecnológica (BEZERRA, 2006). Não obstante aos avanços das políticas científicas de incentivo à produção de conhecimento, os recursos injetados ainda são uma incógnita para pesquisadores e candidatos afrodescendentes à pós-graduação nas universidades brasileiras. A oferta de bolsas de estudos para tornar mais eficiente à pós-graduação, não aumenta as oportunidades dos afrodescendentes obterem uma formação qualificada.

Em sua tese de doutorado, intitulada "Negros e Ciência: uma análise sobre inserção acadêmica de intelectuais negros - o mal-estar na sociedade da informação", Silva (2010) critica a dissociação entre ciência e militância. Ela afirma que o fazer militante e o fazer científico permitem a reelaboração de valores e conceitos, a interferência na ordem social estabelecida, o desenho de uma política de empoderamento e a capacidade de reflexão sobre as relações sociais, educativas, econômicas, políticas, dentre outras.

Em “A (cons) ciência da responsabilidade social e ét(n)ica na produção de conhecimento sobre o (a) negro (a) em programas de pós-graduação da Universidade Federal da Paraíba", Silva (2009) constatou que a produção de conhecimento sobre a temática étnico-racial, pelo menos em um programa de pós-graduação em educação, não ultrapassa 2\%. Para Aquino (2010) a academia muitas vezes produz enunciados sobre/para negros e pouco produz com negros e, quando o faz, apaga suas vozes.

\section{A RELAÇÃO ENTRE AFRODESCENDÊNCIA E INCLUSÃO DIGITAL}

\begin{tabular}{l|l|l|l|l|l|l|}
\hline (C) Rev. digit. bibliotecon. cienc. inf. & Campinas, SP & v.11 & n.2 & p.61-75 & maio/ago.2013 & ISSN 1678-765X \\
\hline
\end{tabular}


A tentativa de inclusão digital tem fortes ligações com cenário tecnológico desenhado para a educação no Brasil, em meados de 1930, cuja dinâmica marcou o início de uma trajetória de "modernização", concretizada na década de 1980, quando passamos a ser expectadores do debate político sobre a inserção das TIC's nas instituições de ensino. A partir desse cenário, políticas e projetos foram formulados com a pretensão de pesquisar e desenvolver teorias e métodos para fundamentar o uso de tecnologias intelectuais na educação.

As primeiras iniciativas de uso das tecnologias no âmbito do ensino ocorreram no campo da formação continuada por meio da realização de cursos específicos para professores que atuariam como formadores de professores e exerceriam as suas funções nos laboratórios de informática das escolas. Nesse entremeio das demandas para o acesso e o uso das tecnologias na educação, juntaram-se formadores, legislação oficial (LDB 9394/96, Plano Nacional de Educação (PNE/2000), Parâmetros Curriculares Nacionais (PCN's), Livro Verde da Sociedade da Informação no Brasil e Diretrizes Curriculares Nacionais do Curso de Pedagogia.

Entretanto, o acesso e o uso das tecnologias intelectuais em todos os campos do conhecimento humano apenas vão se intensificar com o surgimento da Sociedade da Informação e do Conhecimento, onde as regras enunciam a necessidade de formação de educadores para compreender e atuar no novo contexto social para o século XXI. Concretamente, não se tem notícias mais contundentes de que políticas públicas foram elaboradas para incluir digitalmente afrodescendentes.

As gestões para inserção do Brasil na sociedade da informação, iniciadas em 1996, culminaram com as diretrizes do "Livro Verde da Sociedade da Informação no Brasil" e do "Livro Branco" para implementação do Programa Sociedade da Informação. Este propunha a integração, a coordenação e o fomento às ações incentivadoras do uso das tecnologias visando possibilitar a inclusão digital nessa sociedade que se perdeu na descrença da possibilidade de afrodescendentes terem acesso pleno às tecnologias.

$\mathrm{Na}$ conexão com os novos papéis da informação e do conhecimento, penso que é importante saber que informação e conhecimento não são sinônimos. É possível considerar que os elementos fragmentados constituem dados que organizados constituem informação. Esta informação é elaborada pelo sujeito que a utiliza 
atribuindo-lhe sentido, interage com o seu contexto e a transforma em conhecimento. $\mathrm{Na}$ apropriação da informação para transformar-se em conhecimento, o sistema educacional impõe barreiras informacionais para afrodescendentes destinando-lhes uma informação inadequada no atual contexto, sem nenhuma ligação com a sua história, cultura e tecnologia.

É preciso atentar para um ponto crucial: a atual revolução tecnológica surge como uma nova cultura que impõe uma ordem econômica e social e impulsiona o acesso e uso da informação nas diversas atividades humanas e para educação coloca a responsabilidade social de se adequar a esse novo modo de desenvolvimento e redefinir seus espaços de formação. Entretanto, essa cultura que constitui uma das instâncias em potencial para o afrodescendente se empoderar, organizar a sua identidade, superar barreiras, se abastecer com "repertórios culturais diferentes" (CANCLINI, 2007) e se apropriar de fluxos de informação, é negada em sua totalidade.

A propósito, em sua dissertação de mestrado, intitulada "Identidades afrodescendentes: acesso e democratização da informação na cibercultura", Lima (2009) afirmou que "a problemática das identidades afrodescendentes na cibercultura, em alguns casos, esbarra nas barreiras informacionais ou obstáculos informacionais". Ela também comenta que a informação desqualificada é destinada aos afrodescendentes, submetendo-os a uma identidade que não corresponde ao que realmente são. Conclui que a construção da identidade exige a organização da informação produzida de todos os grupos sociais.

$\mathrm{Na}$ investida de reorganização do mundo em torno da democracia de mercado, o projeto de educação para o cidadão adequar-se à cultura digital acaba por dificultar a possibilidade de afrodescendentes terem acesso a uma formação técnico-científica atualizada e efetiva por meio de aparatos tecnológicos sofisticados. Essa dificuldade desconstrói o argumento do Programa da Sociedade da Informação no Brasil, cuja tônica do discurso

É a educação o elemento-chave para a construção de uma sociedade da informação e condição essencial para que pessoas e organizações estejam aptas a lidar com o novo, a criar e, assim, a garantir seu espaço de liberdade e autonomia. A dinâmica da sociedade da informação requer educação continuada ao longo da vida, que permita ao indivíduo não 
apenas acompanhar as mudanças tecnológicas, mas sobretudo inovar (TAKAHASHI, 2000, p.7) .

Tal discurso se mostra enfraquecido para um contingente enorme de afrodescendentes não apenas desconectados, mas vistos como consumidores de produtos oferecidos pelo mercado tecnológico. Os novos instrumentos de compreensão do mundo, os diversos tipos de formação, o novo "estado de aprendência" e a validação do conhecimento como potencializadores para inclusão digital e cidadania étnico-racial ainda estão longe dos afrodescendentes.

A educação tem uma conexão com a informação, mas, segundo Tedesco (2004, p. 23), “o problema para a educação na atualidade não é encontrar a informação, mas como oferecer acesso a ela sem exclusões e, ao mesmo tempo, aprender e ensinar a selecioná-la, avaliá-la, interpretá-la, classificá-la e usá-la". Somado a isto, assegura o autor, os educadores têm de encarar que

"a escola deixa de ser o principal meio de informação para as novas gerações e deve concorrer com outros meios, como a televisão e a Internet, da qual se espera, ademais, que ela informe e ensine" (TEDESCO, 2004, p.25). Nesta direção, encontramos um posicionamento de Sodré (2010) que recoloca a responsabilidade da escola no sentido de redefinir "[...] a partir de um horizonte cultural mais interativo, incluindo jovens e adultos no exercício de interação social, constituído pelas tecnologias [intelectuais] e, consequentemente, pelas novas práticas de escrita e leitura".

É certo que a concepção de uma educação fundamentada apenas na informação sem reflexão, sem o reconhecimento da exclusão digital e sem a negação das diferenças dificilmente poderá gerar "uma maior equidade ou a democratização participativa" (CANCLINI, 2007, p. 234). Segundo Touraine (1998), o sentido da democratização da informação precisa estar alicerçado numa concepção dos direitos do homem, incluindo uma série de direitos (informação, educação, habitação, saúde etc.), que devem apropriados de forma qualitativa por todos os sujeitos.

$\mathrm{O}$ acesso e o uso da informação, como preconizam os idealizadores da sociedade da informação, não democratizam a educação nem favorecem o crescimento das oportunidades de participação concreta de afrodescendentes na 
cultura digital. Essa ideia de democracia implica uma responsabilidade inseparável da diversidade cultural, reconhecendo as diferenças que nos aproximam da posição de que não existe sociedade da informação sem o reconhecimento da exclusão e da necessidade de democratização da informação.

Essa discussão sobre democracia é aprofundada por Sodré (2010) ao reconhecer que não "há democracia, nem inclusão digital por igual", mas essa inclusão, para ele, não se dissocia da "cidadania com as novas formas públicas de cultura” que com a presença das tecnologias dita as normas: “[...] quem está de fora dos novos modos de ler e escrever é tido como excluído do mundo do trabalho e da cultura". É necessário reforçar as políticas de ações afirmativas, mediadas pelos intelectuais negros que estão militando pelas injustiças sociais, a fim de que formulem políticas menos perversas de informação e pela cidadania, sem perder de vista os instrumentos de eliminação das discriminações e racismos na partilha da informação.

As aberturas e os espaços que deveriam ser destinados a afrodescendentes, na era da informação, têm sido historicamente ocupados por aqueles que sempre estiveram dentro do sistema de produção e ainda continuam gozando de privilégios e benefícios. Permanecem fora do campo de visão dos governos e dos produtores de tecnologias intelectuais, a perversa exclusão das sociedades multiétnicas e multiculturais, a negação das múltiplas formas de pertencimento, as exclusões de grupos étnicos. Em consequência dos efeitos da globalização econômica, estes grupos desenvolvem conflitos entre vários grupos em defesa de seus valores, costumes, tradições e identidades.

Os sistemas de informação e comunicação estão restritos a quem tem o poder de decisão. Quem tem mais informação, tem mais conhecimento e poder. Para Tedesco (2004, p. 23), "o conhecimento sempre implica informação e o manejo da informação sobre o conhecimento" (conhecimento especializado). Incluir afrodescendentes digitalmente é uma responsabilidade social que exige novas estratégias de inclusão digital. Essa inclusão, muitas vezes concebida como simples aquisição da informação, tende a criar novas diferenças e aumentar as desigualdades raciais. Incluir afrodescendentes implica também expandir as atuais políticas de informação no sentido de serem pensadas considerando as demandas de diferentes 
grupos e as particularidades de cada contexto, a competência na organização dos conteúdos e das ações para identificar a discriminação racial, propor soluções e ajudar a reduzir os problemas já existentes.

A inclusão de afrodescendentes na era da informação é uma responsabilidade social a ser enfrentada pela educação brasileira. Para além da obrigatoriedade e cumprimento da Lei 10. 639/2003, sua inclusão implica em responsabilidade social com a transmissão do saber sistematizado, com a condução da formação de afrodescendentes respeitando a sua cultura e oferecendo condições dignas para serem capazes de fazer, conhecer, ser e conviver na atual sociedade e participarem da relação com o outro. Caso contrário, essa revolução da cultura digital não passará de uma "revolução imaginária" (TOURAINE, 1998b) para eles, ou melhor, este momento de libertação e de empoderamento de afrodescendentes se tornará impossível se não forem reconhecidos todos os direitos dos sujeitos nem tornará o caminho para a democratização da informação possível.

Há quem apague as esperanças e "o fim das certezas" de inclusão de afrodescendentes, por entender que as exclusões agregaram mais uma nova dimensão às diversas desigualdades sociais e raciais já existentes, que se encaminham no sentido do "acesso desigual ao conjunto de novos bens e serviços associados às tecnologias" (SORJ, 2005, p. 15). A aliada a esta questão, as políticas de inclusão digital não favorecem o contingente de "diferentes, desconectados e desiguais" (CANCLÍNI, 2007, p.16). Nessa ânsia de ter mais e "apagar" o mapa da exclusão, os donos do poder propõe aos afrodescendentes que se afinem com a globalização como trabalhadores e consumidores em um mercado mais exigente em qualificação técnica e flexível. Eles cada vez menos protegidos pelos direitos, como ressalta Canclini (2007, p.211) "mergulham nas franjas massivas do consumo" para vender os produtos, sendo subcontratados, subalternizados e empregados nessas oportunidades eventuais, dentro de uma lógica por tempo limitado e movido por um futuro de incertezas.

Na opinião de Santos (2005),

“a exclusão digital significa a exclusão do conhecimento, que é a pior das exclusões porque de fato retira das pessoas a possibilidade de mudar sua vida e de repensar seu entorno, inclusive a possibilidade de participar democraticamente" 
(SANTOS, 2005, p. 27). Com isso aumenta a disparidade entre informatizados e não informatizados, incluídos e não-incluídos e estes assistem cotidianamente "uma paisagem desencantada" da era da informação.

O Mapa das Desigualdades Digitais no Brasil/2007 mostra que a discriminação por cor ou raça dos indivíduos é também um dos fatores que interferem nas condições de acesso à informação disponibilizada pela internet. Este mapa aponta que

\begin{abstract}
" $28,3 \%$ dos brancos de 10 anos ou mais de idade manifestaram ter usado a Internet nos 3 meses anteriores à pesquisa. Já entre os negros, esse percentual cai para $13,3 \%$ [...] brancos acessam a Internet 2,1 vezes mais que os negros, isto é, mais que o dobro que negros" (WAISELFISZ, 2007).
\end{abstract}

Em sua pesquisa, Lima (2009) constatou que os alunos eram obrigados a optar entre a realização de pesquisas escolares e as atividades de lazer e entretenimento, colocando-os em desvantagens opostas de acesso aos demais jovens ou "ricos de informações". Agrega-se a essa constatação, a afirmação de Canclini (2007, p. 236): "na falta destas condições contextuais, a conexão a redes de informação oferece saberes de baixa ou nenhuma utilização".

As críticas colocadas para essas formas de inclusão digital vêm se processando em nosso país e apontam que os computadores nas escolas para os alunos e os centros gratuitos de acesso para a população em situação de desigualdades beneficiam em maior proporção aos grupos privilegiados. Os índices de inclusão alcançam apenas $2,5 \%$ no uso do computador na escola, enquanto sobe para $37,3 \%$ no grupo de alunos de maior nível de renda. As desigualdades evidenciadas, nestes dados,

\footnotetext{
"nada mais são que uma nova forma de manifestação das tradicionais diferenças e divisões existentes em nossas sociedades e no mundo, novas formas de exclusão que reproduzem e reforçam as diferenças préexistentes" (WAISELFISZ, 2007).
}

\title{
CONSIDERAÇÕES FINAIS
}

O desafio de promover a inclusão digital, certamente, não é responsabilidade social apenas do poder público, nem do movimento negro, mas exige a participação e 
a luta colaborativa de toda a sociedade com ações que ampliem os mecanismos de inclusão digital/etnicorracial para a superação da exclusão digital. É evidente que uma parcela importante dessa responsabilidade precisa ser assumida pelas escolas e universidades públicas, cabendo a estas últimas desenvolverem e democratizarem o conhecimento científico-tecnológico como mecanismo estratégico para o desenvolvimento humano. Deste conhecimento precisam os afrodescendentes se apropriar.

As universidades devem exercitar sua responsabilidade social no sentido de promover a formação técnico-científica, tornar os alunos cidadãos responsáveis e refletir sobre as populações marginalizadas e excluídas. Essa responsabilidade social diz respeito, também, ao papel específico desempenhado pelos intelectuais negros atuantes nas universidades públicas, nas escolas ou na militância. Nas universidades, os intelectuais negros têm um papel importante no processo de formulação das políticas públicas, trabalhando ativamente para implementação dessas políticas, tendo o conhecimento científico como principal instrumento de pressão (SILVA, 2010).

Os instrumentos aparentemente inclusivos estão caminhando muito menos na direção do empoderamento de afrodescendentes na perspectiva de acesso e uso das tecnologias intelectuais, do que no sentido da desconstrução da identidade desse grupo. Por outro lado, se a responsabilidade no acesso e uso das tecnologias não for aceita como parte da educação de afrodescendentes, dificilmente poderá ocorrer a redução das injustiças sociais e das desigualdades raciais. A inclusão digital supõe articulação da parte de intelectuais negros com as Universidades, as Escolas, o Estado, o Movimento Negro, as ONGs e os demais setores da sociedade, posto que se essa inclusão não for da responsabilidade social de todos nós, a nova educação que desejamos dificilmente acontecerá.

A apropriação das tecnologias intelectuais pelos afrodescendentes inclui o uso da internet nas escolas, nas bibliotecas, nos museus, nos telecentros etc. Nas escolas, a inclusão digital não requer apenas a articulação conjunta de fatores administrativos, organizacionais, pedagógicos, técnicos e culturais, nem a informação disponível e acessível mediada pelas bases de dados conectadas, páginas dinâmicas, sites de intranet, bibliotecas digitais. Ela exige as reais condições de acesso e uso, porque o 
número de afrodescendentes que têm computadores e acessam a internet ainda é mínimo.

O pensador indiano Hans Jonas (2006) sugere a urgente definição de novos valores, de novas estratégias, de novas formas de expressão e de representatividade política, de novas formas de governabilidade em todas as instâncias e níveis. Ao contrário, a proposta de consolidação da sociedade da informação para o Brasil poderá perder a sua validade, enquanto um discurso que se propõe a assegurar a informação e o conhecimento sem discriminações de qualquer natureza. $\mathrm{O}$ fato é que ainda se retrai diante da responsabilidade social de incluir afrodescendentes, ficando estes excluídos dos benefícios que as tecnologias intelectuais e a ciência podem oferecer.

É necessário também investir na formação técnico-científica de alunos negros no Ensino Fundamental e Ensino Básico. Tal demanda exigiria a reestruturação do papel do Estado como promotor do progresso científico e tecnológico e a reestruturação das antigas formas de se conceber a cultura científica que interessa aos afrodescendentes. O reconhecimento das desigualdades raciais por parte dos governos é fundamental para que os afrodescendentes possam inserir-se no contexto da cultura digital, onde as aplicações sociais da tecnologia geradoras de conhecimento são (re) criadas. 


\section{REFERÊNCIAS}

AQUINO, Mirian de Albuquerque. Entre a informação e o conhecimento, imbricam-se tensas relações para inclusão social de negros/as na sociedade contemporânea. Inclusão Social, Brasília, v.4, n.1, p. 45-51, jul/dez. 2010.(a)

AQUINO, Mirian de Albuquerque. O novo "status" da informação e do conhecimento na cultura digital. Informação esociedade: estudos. João Pessoa, v.18, n.1, p.79-100, jan./abr. 2008. Disponível em: <www.bocc.ubi.pt/_esp/autor. php?codautor=681>. Acesso em 10 maio 2010.(b)

AQUINO, Mirian de Albuquerque. Políticas de informação para inclusão de negros afrodescendentes a partir de uma nova compreensão da diversidade cultural. Inclusão Social, Brasília, v. 3, n. 2, p.25-35, jan/jun., 2010.(c)

ASSMANN, Hugo. Metáforas para reencantar a educação: epistemologia e didática. Piracicaba:UNIMEP, 2001.

BEZERRA, Lebiam Tamar Silva. A docência do século 21: formando competências para o uso das Tics na UFPB. 2006. Dissertação (Mestrado em Educação) - Faculdade de Educação, Universidade Federal da Paraíba, João Pessoa.

CANCLINI, Nestor Garcia. Diferentes, desiguais e desconectados. Rio de janeiro: UERJ, 2007.

CASTELLS, Manuel. A sociedade em rede. Rio de Janeiro: Paz e Terra, 1999.

CUNHA JÚNIOR, Henrique. A formação de pesquisadores negros no Brasil - Plano 500 de Política Científica Nacional (uma proposta de um pesquisador militante). Disponível em: <www.espacoacademico.com.br/027/27ccunha.htm>Acesso: 02 mai 2010.

DELORS, Jacques (org.). Educação - um tesouro a descobrir. 3. ed. São Paulo: Cortez; Brasília, DF: MEC: UNESCO, 1999. 288 p.

GHIRALDELLI JR., Paulo. O que é pedagogia. 3. ed. São Paulo: Brasiliense

JONAS, Hans. O princípio responsabilidade: ensaio de uma ética para a civilização tecnológica. Rio de Janeiro: Contraponto : Ed. PUC-Rio, 2006.

LÉVY, Pierre. As tecnologias da inteligência: o futuro do pensamento na era da informática. Rio de Janeiro: Editora 34, 1993.

LIMA, Celly Brito de. Identidades afrodescendentes: acesso e democratização da informação na cibercultura. 2009. Dissertação (Mestrado em Ciência da Informação) Universidade Federal da Paraíba, João Pessoa.

OLIVEIRA, Henry Pôncio Cruz. Informação etnicorracial e memória afrodescendente: uma análise do projeto “A cor da cultura”. Projeto de Qualificação (Ciência da Informação). João Pessoa : UFPB, 2010. 
SANTOS, Renato. A inclusão digital requer novo pacto social entre governos e sociedade. Inclusão Social, Brasília, v. 1, n. 1, p. 24-27, out./mar., 2005.

SILVA, Alba Lígia de Almeida. A (cons) ciência da responsabilidade social e ét(n) ica na produção de conhecimento sobre o (a) negro (a) em programas de pós-graduação da Universidade Federal da Paraíba. 2009. Dissertação (Mestrado em Ciência da Informação)

- Universidade Federal da Paraíba, João Pessoa.

SILVA, Eliane Borges. Negros e ciência: uma análise sobre inserção acadêmica de intelectuais negros - o mal-estar na sociedade da informação. 2010. Tese (Doutorado em Ciência da Informação) - PPGCI/UFF/IBICT, Rio de Janeiro.

SODRÉ, Muniz. A interação humana atravessada pela midiatização. IHU On-Line, São Leopoldo, edição 289, 2009. Entrevista concedida a Graziela Wolfart em 13 abr. 2009. Disponível em: www.ihuonline.unisinos.br/index.php?. Acesso em: 03 maio 2010.

SORJ, Bernardo; GUEDES, Luís Eduardo. Exclusão digital: problemas conceituais, evidências empíricas e políticas públicas. Novos Estudos - CEBRAP [on-line]. 2005, n. 72, p. 101-117. Disponível em: <http://www.scielo.br/scielo. php?pid=S0101 33002005000200006\&script=sci_arttext\&tlng=en>. Acesso em 28 nov. 2008.

TEDESCO, Juan Carlos (Org). Educação e novas tecnologias: esperança ou incerteza. São Paulo: Cortez ; Brasília: UNESCO, 2004.

TAKAHASHI, Tadao (Org.) Sociedade da informação no Brasil: livro verde. Brasília: Ministério da Ciência e Tecnologia, 2000.

TOURAINE, Alain. Igualdade e diversidade: o sujeito democrático. Bauru: EDUSC, 1998.

TOURAINE, Alain. Poderemos viver juntos? Petrópolis: Vozes, 1998.

WAISELFISZ, Julio Jacobo. Mapa das desigualdades digitais no Brasil. Brasília: RITLA; Instituto Sangari; Ministério da Educação, 2007.

XAVIER, Juarez. O papel decisivo das pesquisas para o conhecimento dos valores ancestrais afrodescendentes. In: BRAGA, Maria Lúcia de Santana et al. Dimensões da inclusão no ensino médio: mercado de trabalho, religiosidade e educação brasileira. Brasília :

MEC/SECAD, 2006.

\section{Como citar este artigo:}

AQUINO, Mirian de Albuquerque. A inclusão afrodescendente na era da informação. Rev. digit. bibliotecon. cienc. inf., Campinas, SP, v. 11, n. 2, p.61-75, maio/ago. 2013. ISSN 1678-765X. Disponível em: <http://www.sbu.unicamp.br/seer/ojs/index.php/rbci> 